\title{
Natural Fiber Filament Wound Composites: A Review
}

\author{
Suriyati Mohamed Ansari ${ }^{1,{ }^{*}}$, Che Mohd Ruzaidi Ghazali ${ }^{2,3}$, and Kamarudin Husin ${ }^{1,2}$ \\ ${ }^{1}$ Center of Excellence Geopolymer and Green Technology (CEGeoGTech), Universiti Malaysia Perlis \\ (UniMAP), Malaysia \\ ${ }^{2}$ Faculty of Engineering Technology, Uniciti Alam Campus, Universiti Malaysia Perlis (UniMAP), \\ 02100, Sungai ChuChuh, Padang Besar, Perlis, Malaysia \\ ${ }^{3}$ School of Fundamental Science, Universiti Malaysia Terengganu, 21030 Kuala Terengganu, \\ Terengganu
}

\begin{abstract}
In recent development, natural fibers have attracted the interest of engineers, researchers, professionals and scientists all over the world as an alternative reinforcement for fiber reinforced polymer composites. This is due to its superior properties such as high specific strength, low weight, low cost, fairly good mechanical properties, non-abrasive, eco-friendly and bio-degradable characteristics. In this point of view, natural fiber-polymer composites (NFPCs) are becoming increasingly utilized in a wide variety of applications because they represent an ecological and inexpensive alternative to conventional petroleum-derived materials. On the other hand, considerable amounts of organic waste and residue from the industrial and agricultural processes are still underutilized as low-value energy sources. This is a comprehensive review discussing about natural fiber reinforced composite produced by filament winding technique.
\end{abstract}

\section{Introduction}

In the past few decades, research and engineering interest has been shifting from monolithic materials to fiber-reinforced polymeric materials. Fiber reinforced polymers (FRP) are composite materials comprised of a polymer matrix combined with high-strength fibers such as glass, aramid and carbon. These composite materials such as carbon and glass fiber reinforced plastics has dominated the aerospace, leisure, automotive, constructions and sporting industries. Although these composites materials exhibit excellent mechanical properties, they also give rise to environmental pollution due to their non-degradability [1, 2]. Glass fibers are the most widely used material to reinforced plastics due to their low cost compare to other materials and have fairly good mechanical properties. However, these fibers have serious drawback as indicated in Table 1 where the properties of glass fiber were compared with natural fibers. On the other hand, the neutrality properties of natural fibers towards carbon dioxide is particularly attractive. Burning of substances derived from fossil products such as petroleum releases enormous amounts of carbon dioxide into the

${ }^{*}$ Corresponding author: suriyati.mohamed91@gmail.com 
atmosphere. Thus, this phenomenon is believed to be the root cause of the greenhouse effect and by extension the world's climate changes [3].

Built upon those phenomenon, several attempts have been made to use natural fiber composites in place of glass mostly in non-structural applications. As a result, a good number of automotive components previously made with glass fiber composites are now being manufactured using environmental friendly composites [3, 4]. Currently, plenty research materials are being generated on the potential of cellulose based fibers as reinforcement for plastics. However, all researchers that been working in the area of natural fibers and their composites agreed that these renewable abundantly available materials have several feebleness such as; poor wettability, incompatibility with some polymeric matrices and high moisture absorption by the fibers [5].

Table 1. Comparison between natural and glass fibers

\begin{tabular}{|l|l|l|}
\hline & Natural fibers & Glass fibers \\
\hline Density & Low & Twice that of natural fibers \\
\hline Cost & Low & Low, but higher than NF \\
\hline Renewability & Yes & No \\
\hline Recyclability & Yes & No \\
\hline Energy consumption & Low & High \\
\hline Distribution & Wide & Wide \\
\hline $\mathrm{CO}_{2}$ neutral & Yes & No \\
\hline Abrasion to machines & No & Yes \\
\hline Health risk when inhaled & No & Yes \\
\hline Disposal & Biodegradable & Non-biodegradable \\
\hline
\end{tabular}

A composite is a structural material that consist of two or more combined constituents that are attached together at microscopic level and not soluble in each other. One constituent is called the reinforcing phase and the one in which it is embedded is called the matrix. The reinforcing phase material may be in the form of fibers, particles, or flakes. The matrix phase materials are generally continuous [6]. In case of that, fiber-matrix adhesion has become the first and most important problem during achieving a good natural fiber reinforced composites. The role of the matrix in a fiber reinforced composite is to transfer the load to the stiff fibers through shear stresses at the interface. A good bond between the polymeric matrix and the fibers was required in this process. Poor adhesion at the interface means that the full capabilities of the composite cannot be exploited and leaves it vulnerable to environmental attacks that may weaken it, thus reducing its life span. Poor mechanical properties of the natural fiber reinforced polymer composites maybe due to insufficient adhesion between hydrophobic polymers and hydrophilic fibers. However, these properties can be improved by [7, 8] physical treatments (cold plasma treatment, corona treatment) and chemical treatment (maleic anhydride, organosilanes, isocyanates, sodium hydroxide, permanganate and peroxide).

\section{Mechanical and physical properties of natural fiber}

The mechanical and physical properties of natural fibers are very important for industrial applications and can contribute to the use of natural fibers in numerous application and can contribute to the use of natural fibers in numerous applications. Thus, various researchers have studied the physical and mechanical properties of natural fiber-reinforced polymer composites [9-12]. Lower density leads lower-weight structures in the automotive industry and aerospace applications [13-16]. Mechanical properties such as tensile properties, 
flexural properties and impact strength are strongly affected by fiber content, as shown in Figure 2 [17]. The tensile properties of jute oil palm fiber hybrid composites are enhanced substantially with increased jute compared with oil palm epoxy composites.

On the other hand, Venkateshwaran et al. [18] studied the mechanical and water absorption properties of banana/sisal-reinforced hybrid composites using fiber length and weight percentage as the main variables. They reported that hybridizations of sisal fibers with banana/epoxy composites of up to $50 \%$ by weight enhance the mechanical properties and degrade the water absorption properties of these fibers. The overall tensile and flexural properties of natural fiber-reinforced polymer hybrid composites are highly dependent on the aspect ratio, moisture absorption tendency, morphology and dimensional stability of the fibers used.

Zampaloni et al. [19] concluded that both tensile and flexural strength that is very similar to the $40 \%$ by weight flax and hemp polypropylene systems contrast the tensile strength is higher and the flexural strength is almost doubled when compared against the coir and sisal systems. Beside that, the effect of weaving patterns and random orientation on the mechanical properties of banana, kenaf, and banana/kenaf fiber-reinforced hybrid polyester composites was studied by Alavudeen et al. [20]. The result reported in this study showed major improved tensile properties compared to the twill type in all the fabricated composites. Moreover, the maximum increase in mechanical strength was observed in the plain woven hybrid composites rather than in randomly oriented composites. Natural fibers have been used to reinforce various polymer matrices. These fibers include bamboo, flax, coir [21-23] softwood, sisal, banana, coir, jute, abaca oil palm (fruit), kenaf oil palm, spider silk and rice husk [24-27].

\section{Mechanical characterization of filament wound tubes}

There is a considerable research that was carried out in order to characterize the mechanical properties of filament wound composites. In most of studies, mechanical constants and characteristics are determined by means of several mechanical tests and analytical studies. The effect of multi axial filament winding on tubular structures of three different winding configurations was studied by P. Mertiny [28]. This study was conducted by comparing the data of $\left[ \pm 45, \pm 60_{2}\right]$ and $\left[ \pm 30, \pm 60_{2}\right]$ with $\left[ \pm 60_{3}\right]$, so called baseline data, under constant ratios of biaxial loads. In this work, two types of failures are distinguished that is functional failure, where leakage of test fluids takes place but the structure still carries load, and structural failure, where the specimen can no longer carry any load. The experimental hoop and axial stresses at both functional and structural failure was evaluated by the researchers, derived the elastic constants for pure hoop and axial loading conditions and studied the failure envelopes. From the research, it can be found that the failure modes depend strongly on applied stress ratio, and matrix damage can be minimized using $\left[ \pm 30, \pm 60_{2}\right]$ configuration. On the other hand, configurations of $\left[ \pm 45, \pm 60_{2}\right]$ and $\left[ \pm 30, \pm 60_{2}\right]$ showed higher functional and structural strength compared to the baseline configuration under hoop-to-axial load ratios smaller than 1 , due to the reduced axial strain in \pm 60 covers; whereas the baseline configuration performed best under pure hoop loading condition.

Soden [29] carried out a study on the effect of winding angle on the mechanical properties of filament wound composites that are subjected to uniaxial and biaxial stresses. Biaxial loading (hoop and axial loadings for lined and unlined specimens at different winding angles and uniaxial compression is applied to tubular specimens. During testing, electrical resistance strain gages are attached to some specimens and the data obtained are analyzed in order to determine elastic constants. Thus, stress-strain curves are plotted using 
the strain data from the strain gages and the axial stress together with hoop stress data evaluated from the burst tests. In this work also, the variation of the failure stresses ate different tests, effect of the wall thickness on the compressive properties, effect of stress concentrations through the gauge length and comparing the stress envelopes in the work and literature for different winding angles were studied.

Ellyin [30] studied the behavior of multidirectional filament wound glass fiber/epoxy tubular structures under biaxial loading The aim of this study is to investigate the effects of the rate and ratio of biaxial loading on failure strength, damage accumulation and monotonic stress-strain behavior of glass reinforced epoxy tubes. In order to achieve that, different hoop to axial stress ratios are employed in testing, then the failures are studied and biaxial failure envelopes of stress and strain are developed and interpreted. Thus, from the study, it can be concluded that strength and stiffness are functions of biaxial stresses, failure modes and damage accumulations at failure are dependent on biaxial stress ratio, and linear elastic behavior of the tubes can only be seen at relatively low temperatures.

Beside that, the fatigue behavior of glass fiber reinforced $\pm 55^{\circ}$ filament wound composite tubes was investigated experimentally by N. Tarakcioglu, L. Gemi and A. Yapici [31]. The specimens that particularly produced from E-glass fiber with epoxy resin are tested at an open ended internal pressure apparatus and the fatigue tests are performed according to the ASTM standard D2992. In this study, six different stress levels based on different percentages of the static strength of the specimen were applied at one frequency. Three damage mechanism are observed during the testing. These mechanisms are identified as crazing, leakage and final failure followed by the number of cycles to these predetermined levels are observed and recorded. From the results, it was shown that there is an analogy between macro and micro damage stages of the specimens. Thus, it can be concluded that at higher stress levels, the final failure of the specimen occurs just after the leakage whereas for low stress levels, there is much more cycles in between leakage and final failure stages.

Another study was carried out by J. Bai, P. Seeleuthner, and P. Bompard [32] which focus in the mechanical behavior of $\pm 55^{\circ}$ filament wound glass fiber/epoxy resin tubes. In this study, the tube was made of six plies of $\pm 55^{\circ}$ winding angle. Under different loading conditions, a series of mechanical tests were performed which is pure tensile loading, pure internal pressure and combined loading. The work mainly discussed on the damage mechanisms under these conditions. It is stated that the damage and failure process can be described by three steps that is initiation of the damage process by microcracking, delamination between the different plies, and the development and coalescence of cracks and delamination in different plies. In this study also, it can be observed that matric cracks occur perpendicular to the tensile direction at that zones free of fibers whereas at the zones where fiber volume fraction is low, microcracks propagated around fiber bundles. At the zone of high fiber volume fraction, the microcracks propagated at the fiber/matrix interfaces.

The analysis of filament wound cylindrical shells under combined centrifugal, pressure and axial loading was studied by P.M. Wild and G.W. Vickers [33]. Both of these researchers developed an analytical procedure to asses the stresses and deformations of filament wound structures under different loading types. The procedure developed is mainly based on classical laminated plate theory, and models both plane stress and plain strain states of a cylindrical shell having a number of sub-layers, which are cylindrically orthotropic. As a result, it can be concluded that when there is no axial loading, benefit of wind angle variation is more significant. On the other hand, if axial loads are present, the benefits of winding angle variation are more considerable under the last ply criterion. 


\section{Kenaf fiber filament wound tubes}

Kenaf is natural reinforcement fiber in which its capability need to be explore so that it can replaced and compared with other common commercial reinforcement materials. The unique advantages which is high strength to weight ratio of composite materials have been supported by the excellent characteristics of the synthetic fibers. The domination of carbon and e-glass fibers are commonly majoring materials in the aeronautic, automotive and industrial sector. However, serious drawbacks are reported from the usage of these fibers such as non-recyclable, high energy required for manufacturing process, health risks when inhaled and non-biodegradable [34]. Thus, as a solution, any materials that are being considered "green" are very important to many researchers and engineers. Several natural fibers have been used and excellent results have been recorded for various non-load bearing applications. Kenaf with scientific name (Hibiscus cannabinus L) as an example of natural fibers that shows a lot of promises as a reinforcement material and used to live among a variety weather conditions [35,36]. Kenaf is gaining attention as a reinforcement material among researchers to develop a product.

Alkbir [37] analyzed the effect of geometry on crashworthiness parameters of natural fiber kenaf. By using hexagonal tubes and hand lay-up process, kenaf fiber mat was formed. By this, they concluded that kenaf hexagonal tubes produces a variation results and indicated that the angle of kenaf tubes reinforced composite hexagonal tubes affected the crashworthiness parameters. On the other hand, an experimental study on the dynamic mechanical property of hybridized Kenaf/PALF-reinforced HDPE composites were studied by Aji et al. [38]. They mentioned that the presence of the kenaf fiber helps reduce the loss modulus in the dynamic mechanical properties. Yousif et al. [39] conduct an experiment on investigating the effect of untreated and alkali treated kenaf fiber on flexural properties of epoxy composites. From the result, it can be found that reinforcement of epoxy with treated kenaf fibers increased the flexural strength of the composite about $36 \%$ whereas for untreated fiber, there was improvement about $20 \%$. They also stated that the increamental results are mainly due to the high improvement of the chemical treatment $(\mathrm{NaOH})$ on the interfacial adhesion of the fibers and the porosity of the composites which prevented the debonding, detachments or pull out of fibers.

Mokhtar et al. [40] focus a study on experimental analysis of kenaf filament wound tubes under axial compression load. Firstly, axial compression test was performed as an early indication to identify the performance of kenaf filament wound composite tubes. Comparisons have been done towards basalt, e-glass and carbon tubes using polyester as a resin. The axial compression test of kenaf/polyester and kenaf/epoxy tubes were conducted with different winding angles involved which are $45^{\circ}, 55^{\circ}, 65^{\circ}$ and $75^{\circ}$. From the testing it can be seen that $45^{\circ}$ kenaf/epoxy tubes generated the higher compressive strength followed by other winding angle in the ascending order. The layer strength identification has been conducted in 55 winding angle sample in which indicate the increment layer of winding is uniform between one, two and three layers in ascending orders. The comparison between the different reinforcement materials show carbon tubes produced the higher compressive strength followed by e-glass, basalt and kenaf. Kenaf/epoxy recorded 38.7\% lower than the e-glass tubes. Kenaf/epoxy tubes were observed to identify the improvement from kenaf/polyester tubes and results showed at least $22 \%$ increment have been generated. From this experiment, it can be concluded that kenaf presence as a reinforcement material was successfully combine as composite system under axial compressive load as well as lead to the promising indication to be introduced in low bearing application.

Another study on kenaf reinforced composite was studied by S. Misri et al. [41] where the study focusing on the torsional behavior of filament wound kenaf yarn fiber reinforced 
unsaturated polyester composite hollow shafts, with a specific focus on the maximum torsion capacity of the composite hollow shaft for different winding angles and aluminum reinforcement. The conventional filament winding machine was modified and added to a new resin bath mechanism in order to produce a new natural fiber composite hollow shaft using kenaf yarn fiber reinforced with unsaturated polyester resin. It can be found that the torsion capacity is significantly affected by changing the winding angle and the presence of aluminum in the static torque test capacity properties. The torsion test results were obtained in comparison with different orientation between $90^{\circ}$ and $45^{\circ}$ winding angle together with aluminum reinforcement. The results showed that the $45^{\circ}$ orientation filament and aluminum reinforcement in the hollow kenaf composite has the highest value for torsion strength and the longest rotation to crack composite. Finite element analysis (FEA) using Abaqus software 6.10 was carried out and showed a good agreement with the experimental results.

M.H. Zamri et al. [42] investigate on development of green pultruded composites using kenaf fiber: influence of linear mass density on weathering performance. This research reported the performance of pultruded kenaf fiber reinforced composites after exposed to natural weathering condition up to 200 days. Three different linear mass density (Tex) of kenaf yarn fiber that is 1400,2200 and $3300 \mathrm{~g} / \mathrm{km}$ were used as reinforcement material in producing the pultruded composite samples. Fro each composite, moisture content over exposure time and the changes of mechanical properties such as flexural and compression properties were recorded. The result showed that sample made of 3300 linear mass density recorded higher moisture absorption as compared to sample with 1400 linear mass density. Throughout the exposure period, the flexural and compression properties consistently decreased as the absorption of moisture into the composites had weakened the interfacial bonding between kenaf fiber and the matrix resin. However, the pultruded composites that utilized the kenaf fibers with lower fiber linear mass density proved to have better mechanical properties compared to the pultruded composites with a higher number of fiber linear mass density used. Since the degradation started at the point where the kenaf fiber is directly exposed to the environment, the protective layer such as surfing veil which normally used in pultrusion industry is recommended and expected to slow sown the degradation process when exposed to natural environment.

\section{Conclusion}

Natural fiber reinforced filament wound composite appear to have very bright future for wide range of applications. These filaments wound composite have beneficial properties such as low density, less expensive, and reduced solidity when compared to synthetic filament wound composite products. Using natural fibers as reinforcement for polymeric composites introduced positive effect on the mechanical behavior of polymers. These biocomposite materials with various interesting properties may soon be competitive with the existing conventional filament wound product. However, the present low level of production restricts them for to be applied in industrial application. In addition, its hydrophilic properties make the real challenge to design the product which can be a good candidate for various applications. Thus, further research and improvement should be conducted so that these fully environmental friendly composite can easily be manipulated and can give benefit to all mankind and environmental issues.

We would like to appreciate Center of Excellence Geopolymer and Green Technology (CEGeoGTech), School of Materials Engineering, Universiti Malaysia Perlis and Faculty of Engineering Technology, Universiti Malaysia Perlis. 


\section{References}

1. A. Gr, M, Sanjay, B. Yogesha, Carbon, 30 (2014)

2. M. Thiruchitrambalam, A. Alavudeen, A. Athijayamani, N. Venkateshwaran, A.E. Perumal, Mater. Phys. Mech., 8 (2008)

3. H. Larbig, H. Scherzer, B. Dahlke, Poltrock, J. Cell. Plast., 34 (1998)

4. A Leao, R. Rowell, N. Tavares, Applications of Natural Fibers in Automotive Industry in BrazilThermoforming Process, In: 4th International conference proceedings. Cairo, Egypt: Plenum press, (1997)

5. A. Vazguez, J. Riccieri, L. Carvalho, Polym. Composite, 20,1 (1999)

6. K. Autar, Kaw, Mechanics of Composite Materials, 2nd ed, CRC Press Taylor \& Francis Group, (2006)

7. S. Luo, A. Netravali, Polym. Composite, 20, 3 (1999)

8. I. Racz, H. Hargitai, Int. J. Polym. Mater., 47 (2000)

9. R. Mohjoub, J.M. Yatim, A.R.M. Sam, S.H. Hashemi, Constr. Build. Mater., 55 (2014)

10. P. Herrera Franco, A. Valadez Gonzalez, Compos. A: Appl. Sci. Manuf., 35 (2004)

11. S. Ochi, Mech. Mater., 40 (2008)

12. S.M. Sapuan, A. Leenis, M. Harimi, Y.K. Beng, Mater. Des., 27 (2006)

13. J. Datta, P. Kopczynska, Ind. Crops. Prod., 74 (2015)

14. C. Alves, P. Ferrao, A. Silva, L. Reis, M. Freitas, L. Rodrigues, J. Cleaner Prod., 18 (2010)

15. T. Gurunathan, S. Mohanty, S.K. Nayak, Compos. A: Appl. Sci. Manuf., 77 (2015)

16. B. Yousif, S.T. Lau, S. McWilliam, Tribol. Int., 43 (2010)

17. Y. El Shekeil, S.M. Sapuan, M. Jawaid, O. Al Shuja'a, Mater. Des., 58 (2014)

18. N. Venkateshwaran, A.E. Perumal, A. Alavudeen, M. Thiruchitambalam, Mater. Des., 32 (2011)

19. M. Zampaloni, F. Pourboghrat, S. Yankovich, B. Rodgers, J. Moore, L. Drzal, Compos. A: Appl. Sci. Manuf., 38 (2007)

20. A. Alavudeen, N. Rajini, S. Karthikeyan, M. Thiruchitrambalam, N. Venkateshwaran, Mater Des, 66 (2015)

21. A.V. Vuure, J. Baets, K. Wouters, K. Hendrickx, Mater. Lett., 149 (2015)

22. F. Arrakhiz, M. E. Achaby, A. Kakou, S. Vaudreuil, K. Benmoussa, R. Bouhfid, Mater. Des., 37 (2012)

23. A.C. Manalo, E. Wani, N.A. Zukarnain, W. Karunasena, K.T. Lau, Compos. B: Eng., (2015)

24. A, Bledzki, P. Franciszczak, Z. Osman, M. Elbadawi, Ind. Crops. Prod., 70 (2015)

25. N, Defoirdt, S. Biswas, I.D. Vriese, J.V. Acker, Q. Ahsan, L. Gorbatikh, Compos. A: Appl. Sci. Manuf., 41 (2010)

26. H.Y. Cheung, M.P. Ho, K.T. Lau, F. Cardona, D. Hui, Compos. B: Eng., 40 (2009)

27. E. Ayswarya, K.V. Francis, V. Renju, E.T. Thachil, Mater. Des., 41 (2012)

28. P. Mertiny, F. Ellyin, A. Hothan, Compos. Sci. Technol., 4 (2004)

29. P.D. Soden, R. KIthing, P.C. Tse, Y. Tsavalas, Compos. Sci. Technol., 46 (1992)

30. F. Ellyin, M. Carroll, D. Kujawski, A.S. Chiu, Compos. A: Appl. Sci. Manuf., 28 (1997)

31. N. Tarakcioglu, L. Gemi, A. Yapici, Sci. Technol., 65 (2004)

32. J. Bai, P. Seeleuthner, P. Bompard, Compos. Sci. Technol., 57 (1997)

33. P.M. Wild, G.W. Vickers, Compos. A: Appl. Sci. Manuf., 28, (1997)

34. H.Y. Cheung, M.P. Ho, K.T. Lau, F. Cordona, D. Hui, Compos. B: Eng., 40, 7 (2009)

35. A. Ashori, J. Harun, J. Raverty, M.N.M. Yusoff, Polym. Plast. Technol. Eng., 45, 1 (2006) 
36. I.S. Sapuan, S.M. Zainudin, E.S.K. Abdan, International Journal of Mechanical and Materials Engineering, 4, 3 (2009)

37. M.F.M. Alkbir, S.M. Sapuan, M.R. Ishak, Mater. Des., 60 (2014)

38. I.S. Zainudin, S.M. Sapuan, A. Khalina, M.D. Khairul, Polym. Plast. Technol. Eng., 51, 2 (2012)

39. Yousif, B.F. Shalwan, A. Chin, C.W. Ming, Mater. Des., 40 (2012)

40. Mokhtar, I. Yahaya, M.Y. Kadir, M.R.A. Kambali, Polym. Plast. Technol. Eng., 52, 11 (2013)

41. S. Misri, S.M. Sapuan, Z. Leman, M.R. Ishak, Mater. Des., 65 (2015)

42. M.H. Zamri, M.R. Osman, H.M. Akil, M.H.A. Shahidan, Z.A. Mohd Ishak, J. Cleaner Prod., 125 (2016) 